\title{
Gastroesophageal Reflux and Reflux Oesophageal Strictures in Children with Cornelia de Lange Syndrome
}

\author{
MV Vincent, ND Duncan
}

\section{INTRODUCTION}

Due to the early diagnosis and effective treatment options for gastroesophageal reflux (GER), reflux strictures in children are no longer commonly encountered. We report on two cases of reflux oesophageal strictures occurring in children, both having the rare genetic disorder, Cornelia de Lange syndrome, and discuss their management.

Keywords: Cornelia de Lange syndrome, gastroesophageal reflux, reflux strictures

\section{CASE REPORTS}

Case 1: A five-year old girl was referred to our surgical unit with persistent vomiting and failure to thrive. She was diagnosed with Cornelia de Lange syndrome (CdLS), having the typical facial features, at the age of 14 months. She had numerous previous admissions to her local hospital for gastroesophageal reflux symptoms with associated recurrent respiratory tract infections. During one such admission, she was noted to be severely anaemic with a haemoglobin count of $3 \mathrm{~g} / \mathrm{dL}$.

At presentation she was mildly anaemic $(\mathrm{Hb} 10.3 \mathrm{~g} / \mathrm{dL})$ and weighed $7.2 \mathrm{~kg}\left(<3^{\text {rd }}\right.$ per centile). An upper gastrointestinal contrast study revealed a persistent tight stricture at the junction of the middle and distal third of the oesophagus, though no reflux was demonstrated at the time (Fig. 1). A

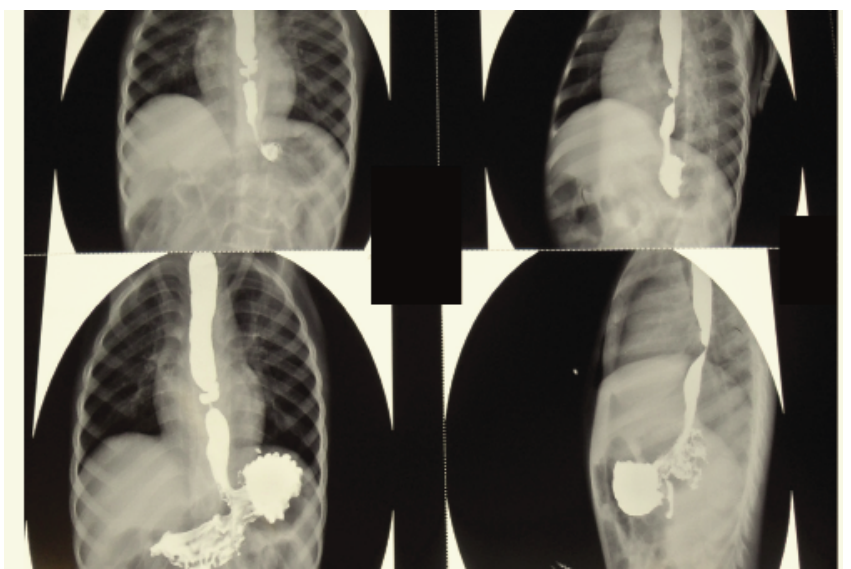

Fig. 1: Upper gastrointestinal contrast study of Case 1 showing stricture at junction of middle and distal third of oesophagus.

From: Department of Surgery, Radiology, Anaesthesia and Intensive Care, The University of the West Indies, Kingston 7, Jamaica, West Indies.

Correspondence: Professor ND Duncan, Department of Surgery, Radiology, Anaesthesia and Intensive Care, The University of the West Indies, Kingston 7, Jamaica, West Indies. E-mail: medicnd@gmail.com
Witzel jejunostomy was performed in order to establish weight gain, following which she gained $6 \mathrm{~kg}$ over a threemonth period.

She then underwent rigid oesophagscopy and stricture dilatation under general anaesthesia. A guide wire was used to negotiate the stricture, which was located at $16 \mathrm{~cm}$ from the incisors and dilated with rigid dilators to a maximum of $27 \mathrm{~F}$. An upper gastrointestinal contrast study performed five days later confirmed a satisfactory outcome with established patency at the previous site of structuring (Fig. 2). She was

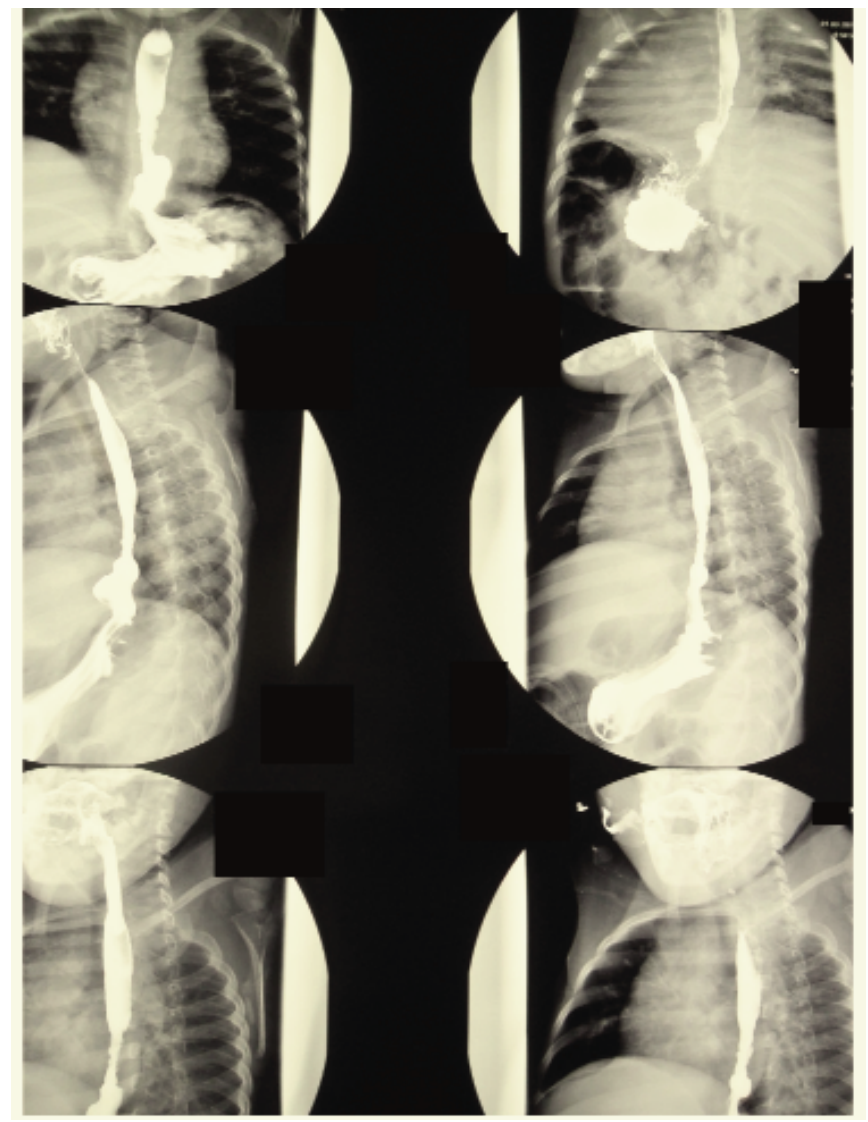

Fig. 2: Upper gastrointestinal contrast study (Case 1) performed five days after oesophageal dilatation.

gradually re-introduced to oral feeds which were initially well tolerated, but she then had an episode of aspiration pneumonia while awaiting definitive surgery.

After fully recovering from aspiration pneumonia, she underwent oesophageal dilatation under general anaesthesia. Rigid bougies were introduced by mouth to dilate the oesophageal stricture, which was maximally dilated to size 28 F. A Nissen's fundoplication and gastrostomy was then performed and the jejunostomy left in situ. 
Postoperatively, the child was noted to have persistently high gastric losses from her gastrostomy in the early postoperative period and was thus started on metoclopramide. Approximately three weeks postoperatively, once oral feeds were re-introduced, vomiting recurred. The decision was thus taken to return to theatre, suspecting wrap failure and some degree of delayed gastric emptying. Intraoperatively, she was noted to have an incompetent wrap (too loose) with dense adhesions to the liver. The adhesions around the wrap were particularly dense posteriorly, making revision treacherous. In light of this, we proceeded to perform a pyloroplasty to decrease the risk of recurrent reflux. Intraoperatively, blood loss was significant, necessitating transfusion of blood and fresh frozen plasma, as well as the insertion of a central line to assist with postoperative resuscitation and monitoring.

She spent two weeks in the intensive care unit after developing acute respiratory distress syndrome (ARDS), following a blood transfusion. Her respiratory problems were also compounded by her previous episodes of aspiration pneumonia. After treatment and resolution of ARDS, she returned to the ward where full gastrostomy feeds were established and the jejunostomy removed.

She was eventually discharged from hospital six weeks following exploratory laparotomy and pyeloplasty. Now at 10 months follow-up, she continues to thrive though she has occasional episodes of vomiting, which are mainly posttussive.

Case 2: A nine-year old boy, who was diagnosed with seizures and Cornelia de Lange syndrome at the age of two years, was referred to our surgical unit with a reflux oesophageal stricture. In addition to the typical facial features of the disorder, he had musculoskeletal manifestations including clinodactyly of the $5^{\text {th }}$ fingers bilaterally and wide gaps between the great and $2^{\text {nd }}$ toes. He had originally presented to his local hospital at the age of eight years with coffeeground vomiting and failure to thrive, and had a barium meal showing no evidence of GER. However, on endoscopy, a reflux stricture was noted in the distal third of his oesophagus and he had undergone seven endoscopic dilations of the stricture prior to referral.

On presentation, he weighed $14.5 \mathrm{~kg}$ (below $3^{\text {rd }}$ percentile). We performed stricture dilatation, a gastrostomy and Nissen's fundoplication. Intraoperatively, the stricture was dilated to size $30 \mathrm{~F}$ and a 3/0 Mersilk suture left in situ passing from gastrostomy to the oral cavity, having traversed the stricture. He had a smooth postoperative recovery and only required one post-fundoplication dilatation two months later. He is currently four years into follow-up and is thriving and tolerating gastrostomy feeds, with occasional oral treats.

\section{DISCUSSION}

The first documented case of the genetic disorder CdLS was made by a German physician, W Brachmann in 1916 (1).
However the condition was later publicized in 1933 by the Dutch paediatrician, Cornelia de Lange, after whom the condition is named.

Cornelia de Lange syndrome is inherited in an autosomal dominant manner with the vast majority of affected individuals having a de novo mutation; less than $1 \%$ of individuals diagnosed have an affected parent (2). Diagnosis is often clinically based, but molecular genetic testing is also available. Mutations in SMC1A are identified in a small percentage of individuals, and in the NIPBL gene in approximately $50 \%$ of patients $(3,4)$.

Clinically, CdLS is marked by severe physical and intellectual developmental anomalies. Physical features include: delayed growth and small stature, microcephaly, hirsutism, nasolacrimal duct obstruction and a series of distinct facial features including low hairline, long eyelashes, thick arched eyebrows that meet in the midline (syrophrys), long philtrum, short up-turned nose, small widely spaced teeth and low-set ears. There is also a propensity for seizures and behavioural problems, particularly self-mutilation and aggression (2). Musculo-skeletal malformations including absence of the upper limbs, absent digits, polydactyly, scoliosis and low bone density are also commonly noted (5, 6). From a surgical point of view, GER $(5,7)$, cardiac septal defects $(8,9)$ and congenital diaphragmatic hernias $(10-12)$ predominate.

Gastroesophageal reflux is almost universal in children with CdLS with over $80 \%$ being affected $(2,13-15)$. This predilection stems from neurological impairment which affects gastroesophageal junction competence, and also causes oropharyngeal (swallowing) dysmotility, oesophageal dysmotility and delayed gastric emptying $(5,13)$. Luzziani (15) also makes note of behavioural factors such as hyperactivity - noted in approximately $85 \%$ of children with CdLS - as a possible contributing factor. In addition, more than $60 \%$ have pathological reflux, including Barrett's oesophagus $(15,16)$, reflux strictures $(6,13)$, and even adenocarcinoma of the oeosphagus (16), all of which tend to present early, usually before age 12 years (6).

Once children with CdLS survive the first two to four years of life during which time aspiration pneumonia is the leading cause of death, overall mortality is reasonably high with survival into the $5^{\text {th }}$ and $6^{\text {th }}$ decades of life being persistently noted (17).

Reflux oesophageal strictures are one of the most problematic complications of GER. Other causes of oesophageal strictures in childhood include children who previously had repair of oesophageal atresias, foreign body ingestion, and, quite commonly, caustic strictures (18-22).

Fortunately, due to early recognition and adequate treatment, the incidence of reflux oesophageal strictures has decreased over the past few decades, from approximately 40 to $50 \%$ of children with GER requiring surgical intervention in the 1960 s and 1970 s $(18,23,24)$ to around $12-20 \%$ today $(21,25)$. 
Reflux oesophageal strictures result from the longstanding insult of peptic juices to the oesophageal mucosa with resulting ulceration, inflammation and secondary fibrosis. With progression, the insult initially spreads to involve the submucosa, and then the muscular layer of the oesophagus. Once the inner circular layer is involved, strictures become apparent. With involvement of the outer longitudinal layer, associated shortening may then occur (21).

The most common mode of presentation of reflux oesophageal strictures in childhood is persistent vomiting, together with failure to thrive and recurrent aspiration pneumonia (18). Chronic blood loss from recurrent upper gastrointestinal bleeding, vomiting of iron-containing foods and use of liquid or semi-solid diets which may be low in iron content frequently leads to iron-deficiency anaemia (18).

Reflux oesophageal strictures, in contrast to strictures secondary to caustic ingestion, are usually short $(1-2 \mathrm{~cm})$ and typically located in the lower or middle third of the oesophagus $(21,25,26)$. A stricture involving the upper thoracic oesophagus is usually secondary to previous surgical interventions for oesophageal atresia or caustic ingestion (19, 21, 22).

Confirming reflux as the cause of oesophageal stricturing is not always easy. Reflux may not be apparent on barium studies, and occasionally 24 hour $\mathrm{pH}$ monitoring may also reveal false negative results (26). The reason for the later observation may be due to the strictured oesophageal segment itself which can act as a barrier to the reflux of gastric acid at the time of the study and hence failure of the 24-hour $\mathrm{pH}$ monitoring sensor to detect a low $\mathrm{pH}$ (26). Oesophagoscopy and biopsy are thus advocated to confirm the diagnosis $(21,26)$, and can also adequately demonstrate the extent of the stricture and assess the feasibility of dilatations. Histology reveals chronic superficial oesophagitis and fibrous replacement of damaged tissue, commencing in the submucosa and spreading outwards (25). Finally, a missed foreign body causing stricturing of the oesophagus may be identified and appropriately removed at endoscopy. (18).

The reported treatment options for children with reflux strictures are quite diverse. While medical management is usually initiated on presentation $-\mathrm{H}_{2}$ receptor antagonists (cimetidine), proton pump inhibitors, and prokinetics (metoclopromide, domperidone, cisapride) - its use in isolation is associated with high failure rates $(18,21,25,27)$.

Surgical options include: bougienage with medical therapy, fundoplication ( \pm gastrostomy) with pre and postoperative dilatations, resection and primary anastomosis and oesophageal replacement.

Because of the short nature of reflux oesophageal strictures in children (average $2 \mathrm{~cm}$ ), response to dilatations is excellent, compared to caustic strictures which are usually longer and more tortuous (21). A single dilatation may be curative. However, several cycles are usually necessary, making this treatment option unattractive for use in children, since it exposes them to the risks of repeated anaesthesia and oesophageal perforation $(21,25,26)$.

There have been many reports of intraoperative oesophageal dilatations performed once, at the time of fundoplication, being sufficient to ameliorate the stricture in most children $(18,23,28)$. However, treatment of the stricture itself prior to fundoplication is advantageous since it ensures resolution of peri-oesophagitis, making fundoplication safer (25).

Fundoplication itself is considered necessary in order to arrest and reverse the pathological changes in the oesophagus, for even dense strictures heal well once reflux is controlled, and the risk of recurrence is dramatically reduced $(5,21,25,26)$.

Many favour the concomitant placement of a gastrostomy whenever a stricture is present, citing the following advantages: it can be used to dilate the oesophagus following fundoplication if strictures recur, it decompresses the stomach with associated decrease in intragastric pressures, which is associated with a reduced risk of wrap disruption, and it enables early enteral feeding $(18,26,29)$. It is also advantageous in neurologically impaired children - including children with CdLS - who invariably have co-existing oesophageal dysmotility and oropharyngeal dysfunction $(5,29)$. The three major factors which predispose children to wrap failure are:

- Operative failure - wrap herniation, wrap slippage, and partial or complete wrap disruption $(30,31)$.

- Neurological impairment, especially when associated with spasticity, scoliosis or seizures - factors associated with increased intra-abdominal pressures (29).

- Delayed gastric emptying, particularly in children older than six years of age (32).

It is thus not surprising that many neurologically impaired children (including children with CdLS) benefit from combined fundoplication and pyloro-plasty (30).

Localized resection is reserved for cases of strictures persisting after an anti-reflux procedure and repeated dilatations $(25,26)$. These resilient strictures are often due to extensive mature fibrosis or fungal infection complicating oesophagitis (25).

When indicated, usually for resilient, reflux oesophageal strictures, the choice for replacement includes an isoperistaltic gastric tube, (33) an anisoperistaltic gastric tube (34) and interposition using either the colon $(34,35)$ or jejunum (36).

Use of gastric interposition is associated with fewer ischaemic complications and an increased likelihood of spontaneous healing of anastomotic leaks due to the stomach's superior vascularity $(33,37,38)$. In addition, gastric interposition is thought to be less technically demanding $(33,36)$. 


\section{CONCLUSION}

In summary, GER is a commonly encountered problem in children with CdLS, who seem to fare worse from its complications $(6,15)$, placing them at an increased risk for Barrett's oesophagus, oesophageal strictures and adenocarcinoma of the oesophagus. It is thus imperative that GER be identified early and treated promptly. Early surgical intervention in the form of anti-reflux surgery and gastrostomy is highly recommended.

\section{REFERENCES}

1. Brachmann W. Ein Fall von symmetrischer Monodaktylie durch Ulnadefekt, mit symmetrischer Flughautbildung in den Ellenbogen, sowie anderen Abnormalitaten (Zwerghaftigkeit, Halsrippen, Behaarung). Jahrbuch Kinderheilkd phys Erzieh 1916; 84: 225.

2. Jackson L, Kline AD, Barr MA, Koch S. de Lange syndrome: a clinical review of 310 individuals. Am J Med Genet 1993; 47: 940-6.

3. Borck G, Redon R, Sanlaville D, Rio M, Prieur M, Lyonnet S et al. NIPBL mutations and genetic heterogeneity in Cornelia de Lange syndrome. J Med Genet 2004; 41: e128

4. Gillis LA, McCallum J, Kaur M, DeScipio C, Yaeger D, Mariani A et al. NIPBL mutational analysis in 120 individuals with Cornelia de Lange syndrome and evaluation of genotype-phenotype correlations. Am J Hum Genet 2004; 75: 610-23.

5. Cates M, Billmire DF, Bull MJ, Grosfeld JL. Gastresophageal dysfunction in Cornelia de Lange syndrome. J Pediatr Surg 1989; 24: 248-50.

6. Kline AD, Grados M, Sponseller P, Levy HP, Blagowidow N, Schoedel $\mathrm{C}$ et al. Natural history of aging in Cornelia de Lange syndrome. Am J Med Genet 2007; 145C: 248-60.

7. Liu J, Krantz ID. Cornelia de Lange syndrome, cohesin and beyond. Clin Genet 2009; 76: 303-14.

8. Mehta AV, Ambalavanan SK. Occurrence of congenital heart disease in children with Brachmann-de Lange syndrome. Am J Med Genet 1997; 71: 434-5.

9. Tsukahara M, Okamoto N, Ohashi H, Kuwajima K, Kondo I, Sugie H et al. Brachmann-de Lange syndrome and congenital heart disease. Am J Med Genet 1998; 75: 441-2.

10. Jelsema RD, Isada NB, Kazzi NJ, Sargent K, Harrison MR, Johnson MP et al. Prenatal diagnosis of congenital diaphragmatic hernia not amenable to prenatal or neonatal repair: Brachmann-de Lange syndrome. Am J Med Genet 1993; 47: 1022-3.

11. Cunniff C, Curry CJ, Carey JC, Graham JM, Williams CA, StengelRutkowski $\mathrm{S}$ et al. Congenital diaphragmatic hernia in the Brachmannde Lange syndrome. Am J Med Genet 1993; 47: 1018-21.

12. Pankau R, Janig U. Diaphragmatic defect in Brachmann-de Lange syndrome: a further observation. Am J Med Genet 1993; 47: 1024-5.

13. Bull MJ, Fitzgerald JF, Heifetz SA, Brei TJ. Gastrointestinal abnormalities: a significant cause of feeding difficulties and failure to thrive in Brachmann-de Lange syndrome. Am J Med Genet 1993; 47: 1029-34.

14. Sommer A. Occurrence of the Sandifer complex in the Brachmann-de Lange syndrome. Am J Med Genet 1993; 47: 1026-8.

15. Luzzani S, Macchini F, Valade A, Milani D, Selicorni A. Gastresophageal reflux and Cornelia de Lange syndrome: typical and atypical symptoms. Am J Med Genet 2003; 119A: 283-7.

16. Macchini F, Fava G, Selicorni A, Torricelli M, Leva E, Valade A. Barrett's esophagus and Cornelia de Lange Syndrome. Acta Paediatr 2010; 99: 1407-10.
17. Beck B, Fenger K. Mortality, pathological findings and causes of death in the de Lange Syndrome. Acta Paediatr Scand 1985; 74: 765-9.

18. Berlatzky Y, Cohen OM, Freund HR, Schiller M. Surgical treatment of gastroesophageal reflux with esophageal stricture in infancy and childhood. Am J Surg 1982; 143: 205-8.

19. Okada T, Ohnuma N, Tanabe M, Iwai J. Effective endless-loop bougienage through the oral cavity and esophagus to the gastrostomy in corrosive esophageal strictures in children. Pediatr Surg Int 1998; 13: $480-6$.

20. Broto J, Asensio M, Jorro CS, Marhuenda C, Vernet JM, Acosta D et al. Conservative treatment of caustic esophageal injuries in children: 20 years of experience. Pediatr Surg Int 1999; 15: 323-5.

21. Briganti V, Oriolo L, Calisti A. Reflux strictures of the oesophagus in children: personal experience with preoperative dilatation followed by anterior fundoplication. Pediatr Surg Int 2003; 19: 544-7.

22. Baskm D, Urganci N, Abbasoglu L, Alkim C. A standardised protocol for the acute management of corrosive ingestion in children. Pediatr Surg Int 2004; 20: 824-8.

23. Boix-Ochoa J, Rehbein F. Esophageal stenosis due to reflux esophagitis. Arch Dis Child 1965; 40: 197-9.

24. Follette D, Fonkalsrud EW, Euler A, Ament M. Gastroesophageal fundoplication for reflux in infants and children. J Pediatr Surg 1976; 11: 757-64.

25. Rhode H, Millar AJW, Brown RA, Cywes S. Reflux stricture of the esophagus in children. J Pediatr Surg 1992; 27: 462-5.

26. Ohhama Y, Tsunoda A, Nishi T, Yamada R, Yamamoto H. Surgical treatment of reflux stricture of the esophagus. J Pediatr Surg 1990; 25: $758-61$.

27. Pattersen DJ, Graham DY, Smith JL, Schwartz JT, Alpert E, Lanza FL et al. Natural history of benign esophageal stricture treated by dilatation. Gastroenterology 1983; 85: 346-50.

28. Vos A, Boerema I. Surgical treatment of gastroesophageal reflux in infants and children. J Pediatr Surg 1971; 6: 101-11.

29. Cheung KM, Tse PWT, Chan KH. Nissen's fundoplication and gastrostomy in neurologically impaired children with gastroesophageal reflux. Hong Kong Med J 2006; 12: 282-8.

30. Fonkalsrud EW, Foglia RP, Ament ME, Berquist W, Vargas J. Operative treatment for the gastroesophageal reflux syndrome in children. J Pediatr Surg 1989; 24: 525-9.

31. Kawahara H, Nakajima K, Yagi M, Okuyama H, Kubota A, Okada A. Mechanisms responsible for recurrent gastroesophageal reflux in neurologically impaired children who underwent laparoscopic Nissen fundoplication. Surg Endosc 2002; 16: 767-71.

32. DiLorenzo C, Piepsz A, Ham H, Cadranel S. Gastric emptying with gastro-oesophageal reflux. Arch Dis Child 1987; 62: 449-53.

33. Borgnon J, Tounian P, Auber F, Larroquet M, Boeris Clemen F, Girardet JP et al. Esophageal replacement in children by an isoperistaltic gastric tube: a 12-year experience. Pediatr Surg Int 2004; 20: 829-33.

34. Anderson KD, Noblett H, Besley R, Randolph JG. Long-term followup of children with colon and gastric tube interposition for esophageal atresia. Surgery 1992; 111: 131-6.

35. Erdogan E, Emir H, Eroglu E, Danismend N, Yeker D. Esophageal replacement using colon: a 15 -year review. Pediatr Surg Int 2000; 16: 546-9.

36. Ring MS, Varco RL, L'heureux PR, Foker JE. Esophageal replacement with jejunum in children. J Thor Cardiovasc Surg 1982; 83: 918-27.

37. Ein SH, Shandling B, Stephens CA. Twenty-one year experience with the pediatric gastric tube. J Pediatr Surg 1987; 22: 77-81.

38. Schettini ST, Pins J. Gastric tube esophagoplasty in children. Pediatr Surg Int 1998; 14: 144-50. 